\title{
Is Better Patient Knowledge Associated with Different Treatment Preferences? A Survey of Patients with Stable Coronary Artery Disease
}

This article was published in the following Dove Press journal: Patient Preference and Adherence

\author{
Neal Yuan (D)' \\ Christy Boscardin ${ }^{2}$ \\ Nadra E Lisha ${ }^{2}$ \\ R Adams Dudley ${ }^{3,4}$ \\ Grace A $\operatorname{Lin}^{2}$ \\ 'Smidt Heart Institute, Cedars-Sinai \\ Medical Center, Los Angeles, CA, USA \\ ${ }^{2}$ Division of General Internal Medicine, \\ Department of Medicine, University of \\ California, San Francisco, CA, USA \\ ${ }^{3}$ Division of Pulmonary, Allergy, Critical \\ Care and Sleep Medicine, Department of \\ Medicine, University of Minnesota, \\ Minneapolis, MN, USA; ${ }^{4}$ School of Public \\ Health, University of Minnesota, \\ Minneapolis, MN, USA
}

Background: In stable coronary artery disease (CAD), shared decision-making (SDM) is encouraged when deciding whether to pursue percutaneous coronary intervention (PCI) given similar cardiovascular outcomes between PCI and medical therapy. However, it remains unclear whether improving patient-provider communication and patient knowledge, the main tenets of SDM, changes patient preferences or the treatment chosen. We explored the relationships between patient-provider communication, patient knowledge, patient preferences, and the treatment received.

Methods: We surveyed stable CAD patients referred for elective cardiac catheterization at seven hospitals from 6/2016 to 9/2018. Surveys assessed patient-provider communication, medical knowledge, and preferences for treatment and decision-making. We verified treatments received by chart review. We used linear and logistic regression to examine relationships between patient-provider communication and knowledge, knowledge and preference, and preference and treatment received.

Results: Eighty-seven patients completed the survey. More discussion of the benefits and risks of both medical therapy and PCI associated with higher patient knowledge scores $(\beta=0.28$, $\mathrm{p}<0.01)$. Patient knowledge level was not associated with preference for $\mathrm{PCI}(\mathrm{OR}=0.78,95 \% \mathrm{CI}$ 0.57-1.03, $\mathrm{p}=0.09$ ). Black patients had more than four times the odds of preferring medical therapy to $\mathrm{PCI}(\mathrm{OR}=4.49,1.22-18.45, \mathrm{p}=0.03)$. Patients preferring medical therapy were not significantly less likely to receive $\mathrm{PCI}(\mathrm{OR}=0.67,0.16-2.52, \mathrm{p}=0.57)$.

Conclusions: While communicating the risks of PCI may improve patient knowledge, this knowledge may not affect patient treatment preferences. Rather, other factors such as race may be significantly more influential on a patient's treatment preferences. Furthermore, patient preferences are still not well reflected in the treatment received. Improving shared decision-making in stable CAD therefore may require not only increasing patient education but also better understanding and including a patient's background and pre-existing beliefs.

Keywords: stable coronary artery disease, stable angina, shared decision-making, percutaneous coronary intervention, stent, optimal medical therapy

\section{Introduction}

For the estimated 10 million Americans with coronary artery disease (CAD), clinical trial evidence has consistently shown that adding percutaneous coronary intervention (PCI) to optimal medical therapy (OMT) does not reduce long-term mortality or risk of cardiovascular events in most patients with stable coronary disease. $^{1-5}$ Rather, the main benefit of PCI appears to be symptom relief, as PCI may ameliorate angina more quickly than OMT alone, but at the expense of
Correspondence: Neal Yuan Smidt Heart Institute, Cedars-Sinai Medical Center, 8700 Beverly Blvd., Davis I0I5, Los Angeles, CA 90048, USA Email Neal.Yuan@cshs.org
Patient Preference and Adherence 2021:15 || 
potential procedure-associated risks. ${ }^{3,6}$ Treatment for stable CAD is thus a classic "preference-sensitive" choice, where the treatment options are comparable in outcomes and as such, treatment decisions should be largely driven by the preferences of a well-informed patient. ${ }^{7,8}$

However, prior studies indicate that many patients have poor understanding of the relative risks and benefits of PCI, often erroneously believing that PCI reduces rates of myocardial infarction and death, while simultaneously underestimating the associated risks of the procedure. ${ }^{9-13}$ Many patients are also not actively engaged in the treatment decision-making process and receive PCI despite having few symptoms and minimal trials of medical therapy. ${ }^{14-17}$

Prior efforts to improve the decision-making process have mainly focused on addressing gaps in patient knowledge through better patient education. ${ }^{18-22}$ Despite evidence that such educational interventions may improve a patient's understanding of the medical facts relevant to the treatment options, no studies to-date have examined whether an improvement in such knowledge changes patient preferences for treatment. It is unknown, for example, whether understanding that PCI may not reduce longterm mortality changes a patient's preference for PCI. There may be other values and beliefs that are not necessarily based in medical knowledge that shape treatment decisions. This is one of the first studies to separate out and assess the individual components of the treatment decision-making process in stable CAD. Our objective was to understand the relationships between patientprovider communication about treatment options, patient knowledge, patient preferences, and the treatment received.

\section{Methods}

\section{Survey Development}

Survey questions were developed through a multi-step process (Supplemental Figure 1). We identified three primary domains of high decision-making quality via literature review and consultation with an expert panel consisting of cardiologists, cardiac surgeons, internists, decision scientists, nurses, and patients: patient-provider communication, knowledge, and preferences. We then developed a pool of 60 questions addressing critical aspects of each domain. The communication questions assessed the patient's perspective on the relative degree of discussion by providers about the risks and benefit of
OMT and PCI for stable CAD. ${ }^{23}$ Knowledge questions tested understanding of the risk and benefits of the treatment options, including that PCI may relieve anginal symptoms sooner, but does not provide additional benefit with respect to cardiovascular events or long-term mortality. The patient preferences section contained questions about desired level of shared decision-making and treatment preference.

The pool of 60 questions was reviewed and ranked for importance, validity, and feasibility by the expert panel using a modified Delphi method. Twenty-five questions with the highest ratings were then chosen for the survey and evaluated through 17 cognitive interviews with patients to confirm question comprehension, response processes, and feasibility of completing the questionnaire. After each set of 3-5 interviews, questions were revised based on participant feedback and-retested with the next set of patients. Once the interviews reflected that the majority of participants were able to understand and complete the questions in a reasonable time, the questions were finalized. The final survey contained 8 communication questions, 11 knowledge questions, and 6 preference questions (Supplemental Data 1). The questionnaire also assessed self-reported demographics, medical history, and degree of symptoms measured by the Seattle Angina Questionnaire (SAQ) score, which ranges from 0 to 100 and can be interpreted as excellent (75-100), good (50-$74)$, fair (25-49), or poor $(0-24){ }^{24}$

\section{Patient Recruitment and Survey Administration}

We recruited patients who had been referred for consideration of elective cardiac catheterization for stable CAD at 7 hospitals: 2 academic medical centers (University of California San Francisco (UCSF), San Francisco, CA; Emory University, Atlanta, GA), 1 community hospital (St. Luke's, Kansas City, MO), 3 safety net hospitals (Zuckerberg San Francisco General (ZSFG), San Francisco, CA; Truman Medical Center, Kansas City, MO; Grady Memorial, Atlanta, GA), and 1 veterans affairs hospital (San Francisco Veterans Affairs (SFVA), San Francisco, CA). Stable CAD was defined as angina without change in frequency or pattern for six weeks prior to enrollment, angina controlled by rest or medication, or an abnormal stress test. Patients were excluded from the study if they were less than 18 years of age, had an indication for cardiac catheterization other than CAD, 
were non-English speaking, or were unable to consent or complete study tasks.

Patients were surveyed directly after their consultation with a cardiologist for the above inclusion criteria by trained study coordinators. Prior to patient enrollment, patients were informed about the purpose of the study and written consent was obtained in accordance with the standards of the Declaration of Helsinki. Since this study sought to characterize the current standard of care, all provider-patient education was given per the cardiologist's discretion during the patient visit and no additional patient education was provided as part of the study.

\section{Survey Scoring}

For the communication questions, patients reported whether physicians had discussed the risks and benefits of each therapy a lot, some, a little, or not at all, corresponding to a numerical scale of 0 to 3 . A score from the knowledge questions was calculated by assigning 1 point for a correct answer and 0 points for an incorrect one. The total possible score was 11 points. Patients indicated their preferences for shared decision-making on a scale from 1 to 5 , with 1 meaning that the patient did not want to be involved in decision-making and 5 meaning that the patient wanted to make decisions completely on their own. Patients also reported how important out-of-pockets costs were in their decision on a scale from 1 to 4 , with 1 meaning no effect and 4 meaning major effect. Preference for treatment was measured by asking patients whether they ultimately would prefer to take medications alone, undergo PCI, or were unsure.

\section{Assessment of Treatment Outcomes}

We conducted chart review to ascertain the results of the cardiac catheterization and whether patient received PCI within 6 months of the initial survey.

\section{Statistical Analysis}

We used multivariable linear regressions to study the relationship between level of patient-provider communication and patient knowledge. We used logistic regression to study the influence of patient knowledge on patient treatment preference as well as treatment preference on treatment received. We included age, gender, race, education level, prior history of PCI, prior history of myocardial infarction, degree of desired patient decision involvement, SAQ score, importance of out-of-pocket costs, and insurance coverage as covariates in our models. To avoid model overfitting, the final multivariable models included only covariates with $\mathrm{p}<0.10$ from age- and sex-adjusted models. All statistical analysis was completed using $\mathrm{R}$ software (version 3.4.1, Vienna, Austria).

This study was approved by the institutional review board at the University of California, San Francisco.

\section{Results \\ Participants}

A total of 87 participants completed the survey (Table 1). Patients were enrolled from all participating medical center sites (UCSF/ZSFG/SFVA: 20 patients, Truman: 20 patients, Emory/Grady: 39 patients, St. Luke's: 8 patients). Patients were predominately older, male, and highly educated - almost $70 \%$ had at least some college education. The sample was $56.3 \%$ white, $32.3 \%$ black, and $11.5 \%$ of

Table I Participant Characteristics

\begin{tabular}{|l|l|}
\hline Characteristics & $\mathbf{N}=87$ \\
\hline Age, $\bar{x} \pm$ SD & $61.3 \pm 9.8$ \\
\hline Female & $34(40.5 \%)$ \\
\hline Race & \\
Black & $28(32.3 \%)$ \\
White & $49(56.3 \%)$ \\
Neither Black or White & $10(11.5 \%)$ \\
\hline Education level & \\
8th grade or less & $1(1.1 \%)$ \\
Some high school & $3(3.4 \%)$ \\
High school graduate or GED & $23(26.4 \%)$ \\
Some college or 2 year degree & $27(31.0 \%)$ \\
4-year college graduate & $16(18.4 \%)$ \\
Advanced degree & $17(19.5 \%)$ \\
Past MI & $20(33.0 \%)$ \\
Past PCI & $31(35.6 \%)$ \\
SAQ, $\bar{x} \pm$ SD & $62.3 \pm 24.3$ \\
\hline Preference for decision-making process & \\
Doctor decides on his/her own & $4(4.6 \%)$ \\
Doctor listens to my opinion and then decides & $13(14.9 \%)$ \\
Doctor and I are equal partners in deciding & $62(71.3 \%)$ \\
I listen to doctor's opinion and then I decide & $8(9.2 \%)$ \\
I decide on my own & $0(0 \%)$ \\
\hline Insurance coverage & $6(6.9 \%)$ \\
Medicaid & $37(42.5 \%)$ \\
Medicare & $30(34.5 \%)$ \\
Private Insurance & $14(16.1 \%)$ \\
Other Insurance or No Insurance & \\
\hline
\end{tabular}

Abbreviations: SD, standard deviation; GED, general education diploma; MI, myocardial infarction; $\mathrm{PCl}$, percutaneous coronary intervention; SAQ, Seattle Angina Questionnaire. 
another race. One-third of the sample had experienced a prior myocardial infarction and $35.6 \%$ had received a prior PCI. Patients had a mean SAQ score of 62.3 (SD $=24.3$ ), indicating on average, good anginal control. The majority of patients expressed a preference for a shared decision-making process. Most patients had either Medicare or private insurance coverage.

\section{Predictors of Knowledge}

Overall knowledge scores were poor, with a mean score of 5.2 ( $\mathrm{SD}=2.4$ ) out of 11 points. We found that most patients recalled having engaged in some or a lot of discussion about the risks and benefits of both OMT and PCI, although there was more discussion about PCI than OMT (Figure 1). Patients who recalled having more discussion with their provider about the risks and benefits of OMT and PCI had significantly higher knowledge scores even after adjustment for age, race, and education level $(\beta=0.28$, $p<0.01$ ) (Figure 2). This relationship remained true when considering only discussions of OMT risks, OMT benefits, PCI risks, or PCI benefits individually.

\section{Predictors of Treatment Preference}

When asked about their treatment preference, 19 (21.8\%) individuals expressed a preference for receiving OMT alone. In the multivariable analysis, a higher knowledge score was not associated with a patient's level of preference for OMT $(\mathrm{OR}=0.85,95 \%$ CI $0.65-1.10, \mathrm{p}=0.21)$ (Table

2 ). We further examined the effect of individual knowledge questions. We found that there was no significant association between treatment preference and whether or not a patient understood that i.) PCI could reduce angina sooner than OMT $(\mathrm{OR}=0.45,0.04-3.38, \mathrm{p}=0.47)$, ii. $)$ PCI did not reduce future risk of $\mathrm{MI}(\mathrm{OR}=2.36,0.45-12.55, \mathrm{p}=0.30)$, or iii.) PCI did not improve survival (OR = 2.16, 0.4-10.2, $\mathrm{p}=0.33$ ). Race was a significant predictor of treatment preference. Black patients were significantly more likely to prefer OMT instead of PCI when compared to nonblack patients $(\mathrm{OR}=4.38,1.09-19.82, \mathrm{p}=0.04)$ (Table 2, Figure 3). A patient with insurance coverage that was not Medicaid, Medicare, or Private had a lower likelihood of preferring OMT $(\mathrm{OR}=0.04,0.00-0.37, \mathrm{p}=0.01)$, although there were few overall patients in this category.

\section{Predictors of Treatment Received}

We found that $26.3 \%$ of patients who preferred medical therapy received PCI within 6 months of the survey; $47.1 \%$ of patients who preferred PCI received PCI. The average time between survey and PCI was 7.76 days (SD 12.2). After multivariable adjustment, a patient's preference for PCI did not significantly predict the chance of receiving $\mathrm{PCI}(\mathrm{OR}=0.41,95 \%$ CI $0.09-1.70, \mathrm{p}=0.24)$ (Table 3). The only statistically significant predictors for receiving PCI was whether a patient had a history of prior


Figure I Amount of provider-patient discussion of the benefits and risks of OMT and PCl as recalled by patients. 


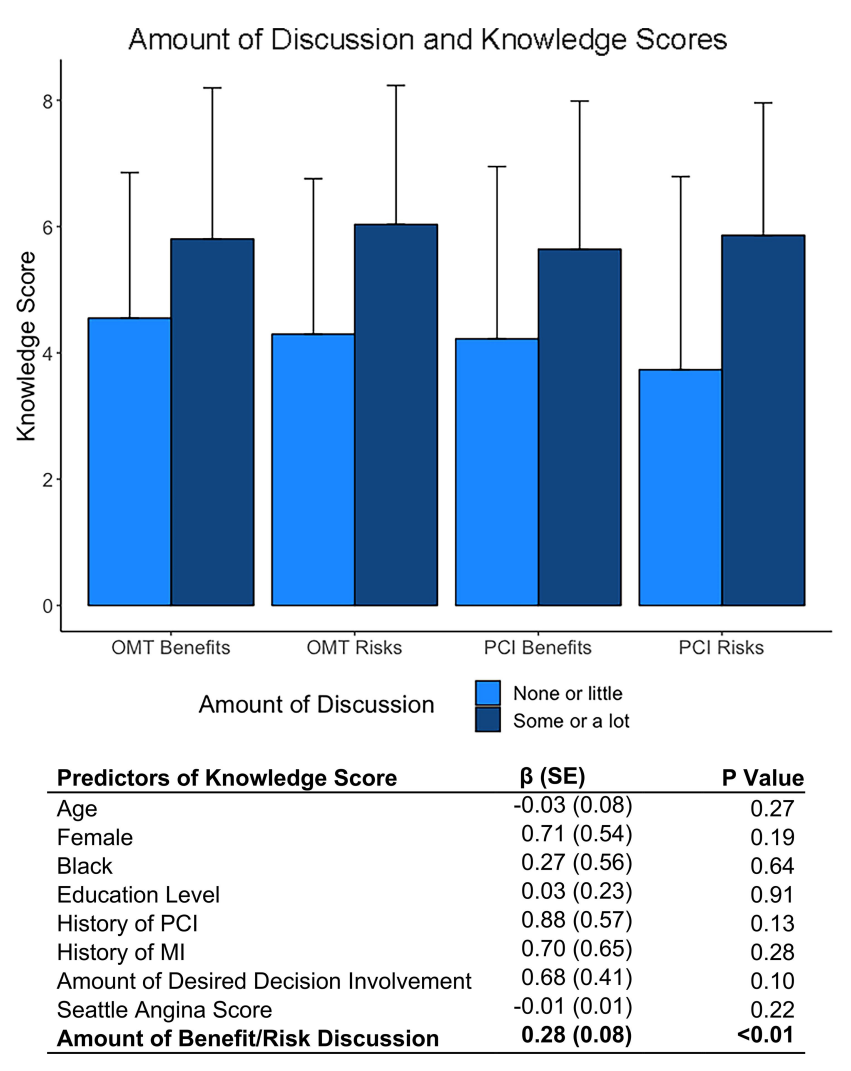

Figure 2 The association between amount of provider-patient benefit/risk discussion and a patient's knowledge scores. Bolded predictors reached a $\mathrm{p}$-value $<0.05$.

PCI $(\mathrm{OR}=5.59,1.76-20.23, \mathrm{p}=0.01)$ and whether a patient had insurance coverage that was not Medicaid, Medicare, or Private $(\mathrm{OR}=0.02,0.00-0.24, \mathrm{p}=0.01)$.

\section{Discussion}

Despite substantial clinical evidence that the addition of PCI to OMT does not decrease future cardiac events or mortality, we found that even in our sample of patients with relatively high levels of education, patient understanding of these facts remains poor. ${ }^{4,9-13}$ Prior efforts to improve decision quality in stable $\mathrm{CAD}$ have focused on closing this knowledge gap. ${ }^{18-22}$ This is one of the first studies to rigorously assess whether more knowledgeable patients in fact make different decisions around stable CAD treatment. We showed that while improving patient knowledge may be necessary, it may not be sufficient for changing a patient's treatment preferences or the treatment received. Other factors such as a patient's race may have more influence.

Consistent with prior research, we showed that more provider-patient discussion about stable CAD treatment risks and benefits was significantly associated with better patient knowledge. However, we found that knowledge of stable CAD treatment options, including understanding that PCI has additional risks without prolonging life or decreasing cardiac events, was not associated with patient treatment preference, even after accounting for demographics, insurance coverage, degree of symptoms, and cardiac disease history. There may be several reasons for this. For some patients, prior experiences and pre-existing health beliefs may be more important than actual medical knowledge during the decision-making process. Studies have highlighted biases based on personal anecdotes and analogies, patient distrust of the healthcare system, and religion, all of which may powerfully affect a patient's beliefs about pursuing medical interventions. ${ }^{11,25-30}$ In our study, race strongly predicted patient preferences with black patients having more than four times the odds of preferring OMT to PCI when compared with non-black patients.

Provider biases may also play a role. For example, prior research has found that providers may have biased perspectives based on race about a patient's likelihood of medical adherence and risky behaviors. ${ }^{31}$ Further studies have shown that providers may unknowingly believe that white patients are more likely to benefit from PCI than minority patients. ${ }^{25,32}$ One study of patients with positive nuclear stress tests studied both patient and physician beliefs and concluded that disparities in coronary catheterization were more likely attributable to biases in physician assessment rather than patient attitudes. ${ }^{26}$ Overall, our study results suggest that efforts to improve patient education that focus on medical knowledge alone without considering both provider- and patient-specific beliefs and experiences will be insufficient in influencing patient preferences for treatment.

The vast majority of patients indicated a desire for shared decision-making. However, we found that more than a quarter of patients who expressed a preference for OMT over PCI still received PCI. A patient's preference was not significantly associated with treatment outcome even after adjusting for patient comorbidities. Given that the indication for PCI in stable CAD is ultimately determined by a patient's assessment of his or her symptom severity, we believe that the decision to pursue PCI should be more significantly influenced by patient preference. This speaks to the ongoing possibility that provider preference plays a stronger role than it should. Indeed, this is consistent with one study that observed patient-provider conversations on stable CAD treatment and revealed that only $14 \%$ of conversations met basic tenets of a shared 
Table 2 Predictors of Patient Preference for OMT Over PCl

\begin{tabular}{|c|c|c|c|c|}
\hline & \multicolumn{2}{|c|}{ Age- and Sex-Adjusted Models } & \multicolumn{2}{|c|}{ Multivariable-Adjusted Model ${ }^{\dagger}$} \\
\hline & OR $(95 \% \mathrm{Cl})$ & p-value & OR $(95 \% \mathrm{Cl})$ & p-value \\
\hline Age & $0.98(0.93-1.04)$ & 0.57 & $1.02(0.95-1.10)$ & 0.64 \\
\hline Female & $0.54(0.18-1.61)$ & 0.27 & $0.78(0.20-3.14)$ & 0.72 \\
\hline Knowledge Score & $0.82(0.64-1.03)$ & 0.09 & $0.85(0.65-1.10)$ & 0.21 \\
\hline Black & 3.38 (1.09-1 I.03) & 0.04 & 4.38 (1.09-19.82) & 0.04 \\
\hline Education Level & $1.09(0.69-1.74)$ & 0.71 & & \\
\hline History of $\mathrm{PCl}$ & $0.23(0.03-0.94)$ & 0.07 & $0.22(0.03-1.07)$ & 0.09 \\
\hline History of Ml & $0.45(0.07-1.90)$ & 0.33 & & \\
\hline Decision Involvement ${ }^{\S}$ & $0.91(0.40-2.17)$ & 0.83 & & \\
\hline Seattle Angina Score & $1.00(0.98-1.03)$ & 0.84 & & \\
\hline Importance of Cost* & $2.29(0.75-7.45)$ & 0.15 & & \\
\hline \multicolumn{5}{|c|}{ Insurance (Ref: Private Insurance)** } \\
\hline Medicaid & $0.98(0.10-7.72)$ & 0.99 & $0.33(0.02-4.71)$ & 0.43 \\
\hline Medicare & $0.20(0.04-0.86)$ & 0.04 & $0.15(0.02-0.94)$ & 0.06 \\
\hline Other & $0.12(0.01-0.77)$ & 0.06 & $0.04(0.00-0.37)$ & 0.01 \\
\hline
\end{tabular}

Notes: Bolded predictors reached a p-value $<0.05$ in the multivariable-adjusted model. ${ }^{\dagger}$ To avoid model overfitting, the multivariable-adjusted model was created by including only age, sex, knowledge score, and predictors with p-value $<0.10$ in age- and sex-adjusted models. ${ }^{\S}$ Decision involvement refers to amount of a patient's desired decision-making involvement (ordinal 5 point scale. I = patient did not want to be involved in decision-making, 5 = patient wanted to make decision completely on their own). *Importance of cost refers to patient-reported importance of out-of-pocket costs in making decision $(0=$ no or minor effect, $\mathrm{I}=$ moderate or major effect). **Insurance odds ratios are in reference to patients with private insurance.

Abbreviations: OMT, optimal medical therapy; PCl, percutaneous coronary intervention; OR, odds ratios; Cl, confidence interval; $\mathrm{Ml}$, myocardial infarction.

decision-making process. This included exploring patient preferences and emphasizing that the patient is ultimately in control of the decision. ${ }^{14}$ While our study was unable to assess why treatment decisions may not match patient preferences, the possible reasons for a provider-driven decision-making process are many and may include factors such as a strong provider belief in benefit for one

\section{Treatment Preference by Race}

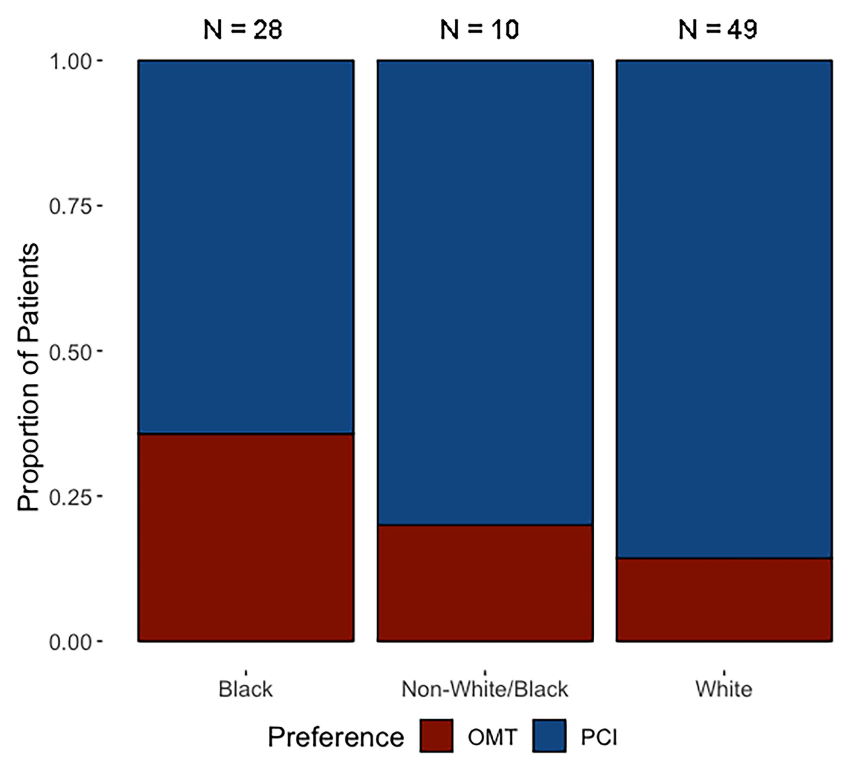

Figure 3 Preferences for stable CAD treatment by patient race. treatment option, bias towards intervention instead of nonaction, or medicolegal concerns, among others. ${ }^{33,34}$ Regardless of the specific reason, though, our results confirm an ongoing need for more inclusion of patient preferences when making treatment decisions in stable CAD.

Several limitations to this study merit consideration. As patient participation in this study was voluntary, we do not know if there was significant bias from patient self-selection. Nevertheless, the patient cohort was diverse and felt to be generally reflective of the patient population with stable CAD. The survey was based on self-reported measures, so there could be recall bias in terms of patients' answers to the survey questions. However, we surveyed patients just after provider visits to minimize recall issues. Our sample size may have been underpowered to detect certain associations including the relationship between patient knowledge and treatment preference as well as treatment preference and treatment received. However, we did find significant relationships consistent with prior research, such as the association between education and patient knowledge, which suggests that our sample was large enough to detect other prior defined associations. The quality of our data was also strong, and we conducted in-depth assessments of patient knowledge and preferences that could be difficult to accomplish in larger patient samples. Nevertheless, additional qualitative studies with more individuals would be helpful for confirming our findings. 
Table 3 Predictors of Receiving PCI

\begin{tabular}{|c|c|c|c|c|}
\hline & \multicolumn{2}{|c|}{ Age- and Sex-Adjusted Models } & \multicolumn{2}{|c|}{ Multivariable-Adjusted Model ${ }^{\dagger}$} \\
\hline & OR $(95 \% \mathrm{CI})$ & p-value & OR $(95 \% \mathrm{Cl})$ & p-value \\
\hline Age & $1.03(0.99-1.09)$ & 0.18 & $1.05(0.98-1.13)$ & 0.20 \\
\hline Female & $1.46(0.59-3.74)$ & 0.42 & $1.65(0.50-5.75)$ & 0.42 \\
\hline Prefer OMT over $\mathrm{PCl}^{\ddagger}$ & $0.55(0.16-I .7 I)$ & 0.32 & $0.4 I(0.09-1.70)$ & 0.24 \\
\hline Black & $0.93(0.35-2.47)$ & 0.88 & & \\
\hline Education Level & $1.10(0.75-1.60)$ & 0.63 & & \\
\hline History of PCI & $4.28(1.58-12.28)$ & 0.01 & $5.59(1.76-20.23)$ & 0.01 \\
\hline History of Ml & $1.82(0.62-5.50)$ & 0.27 & & \\
\hline Decision Involvement ${ }^{\S}$ & $2.38(1.07-6.19)$ & 0.05 & $2.48(0.86-8.36)$ & 0.11 \\
\hline Seattle Angina Score & $1.01(0.99-1.03)$ & 0.27 & & \\
\hline Importance of Cost* & $0.65(0.25-1.64)$ & 0.37 & & \\
\hline \multicolumn{5}{|l|}{ Insurance (Ref: Private Insurance)** } \\
\hline Medicaid/No Insurance & $0.23(0.01-2.14)$ & 0.24 & $0.29(0.01-2.92)$ & 0.34 \\
\hline Medicare & $0.40(0.11-1.29)$ & 0.13 & $0.32(0.06-1.36)$ & 0.14 \\
\hline Other & $0.11(0.01-0.5 I)$ & 0.01 & $0.05(0.00-0.34)$ & 0.01 \\
\hline
\end{tabular}

Notes: Bolded predictors reached a p-value $<0.05$ in the multivariable-adjusted model. ${ }^{\dagger}$ To avoid model overfitting, the multivariable-adjusted model was created by including only age, sex, preference for OMT, and predictors with $\mathrm{p}$-value $<0.10$ in age- and sex-adjusted models. ${ }^{\ddagger}$ Prefer OMTover PCl refers to whether patient expressed an ultimate treatment preference for OMT instead of $\mathrm{PCl}$. ${ }^{\S}$ Decision involvement refers to amount of a patient's desired decision-making involvement (ordinal 5 point scale. I = patient did not want to be involved in decision-making, 5 = patient wanted to make decision completely on their own). *Importance of cost refers to patient-reported importance of out-of-pocket costs in making decision $(0=$ no or minor effect, $\mathrm{I}=$ moderate or major effect). **Insurance odds ratios are in reference to patients with private insurance.

Abbreviations: OMT, optimal medical therapy; PCl, percutaneous coronary intervention; OR, odds ratios; Cl, confidence interval; Ml, myocardial infarction.

\section{Conclusion}

The treatment decision-making process for patients with stable CAD is complex, and patient medical knowledge is likely not the only factor influencing patient decisions. Discussing the benefits and risks of stable CAD treatment with patients may improve patient knowledge; however, greater knowledge may not predict a patient's treatment preference or the treatment received. Improving the quality of shared decision-making for patients with stable CAD will thus require a broader approach including not only improvements in patient education but also a better understanding of the role of the patient's background, preexisting beliefs, and relationship with the physician.

\section{Funding}

National Heart, Lung, and Blood Institute R01 HL114918; Agency for Healthcare Research and Quality K08 HS17723. The funding agreement ensured the authors' independence in designing the study, interpreting the data, writing, and publishing the report.

\section{Disclosure}

Neal Yuan, M.D., Christy Boscardin, Ph.D., Nadra E. Lisha, Ph.D., R. Adams Dudley, M.D., M.B.A., and Grace A. Lin, M.D. report no conflicts of interest.

\section{References}

1. Maron DJ, Hochman JS, Reynolds HR, et al. Initial invasive or conservative strategy for stable coronary disease. $N$ Engl J Med. 2020;382(15):1395-1407. doi:10.1056/NEJMoa1915922

2. Lloyd-Jones D, Adams RJ, Brown TM, et al. Executive summary: heart disease and stroke statistics-2010 update: a report from the American heart association. Circulation. 2010;121(7):948-954. doi:10.1161/CIRCULATIONAHA.109.192666

3. Boden WE, O'Rourke RA, Teo KK, et al. Optimal medical therapy with or without PCI for stable coronary disease. $N$ Engl $J$ Med. 2007;356(15):1503-1516. doi:10.1056/NEJMoa070829

4. Al-Lamee R, Thompson D, Dehbi H-M, et al. Percutaneous coronary intervention in stable angina (ORBITA): a double-blind, randomised controlled trial. Lancet. 2018;391(10115):31-40. doi:10.1016/S01406736(17)32714-9

5. BARI 2D Study Group. A randomized trial of therapies for type 2 diabetes and coronary artery disease. $N$ Engl J Med. 2009;360 (24):2503-2515. doi:10.1056/NEJMoa0805796

6. Bangalore S, Pursnani S, Kumar S, Bagos PG. Percutaneous coronary intervention versus optimal medical therapy for prevention of spontaneous myocardial infarction in subjects with stable ischemic heart disease. Circulation. 2013;127(7):769-781. doi:10.1161/CIRCULA TIONAHA.112.131961

7. Dartmouth Atlas of Health Care. Preference-sensitive care. Available from: http://www.dartmouthatlas.org/keyissues/issue.aspx?con=2938. Accessed August 9, 2016.

8. Fowler FJ, Levin CA, Sepucha KR. Informing and involving patients to improve the quality of medical decisions. Health Aff. 2011;30 (4):699-706. doi:10.1377/hlthaff.2011.0003

9. Rothberg MB, Sivalingam SK, Ashraf J, et al. Patients' and cardiologists' perceptions of the benefits of percutaneous coronary intervention for stable coronary disease. Ann Intern Med. 2010;153(5):307-313. doi:10.7326/0003-4819-153-5-20100907000005 
10. Holmboe ES, Fiellin DA, Cusanelli E, Remetz M, Krumholz HM. Perceptions of benefit and risk of patients undergoing first-time elective percutaneous coronary revascularization. $J$ Gen Intern Med. 2000;15(9):632-637. doi:10.1046/j.1525-1497.2000.90823.x

11. Whittle J, Conigliaro J, Good CB, Kelley ME, Skanderson M. Understanding of the benefits of coronary revascularization procedures among patients who are offered such procedures. Am Heart $J$. 2007;154(4):662-668. doi:10.1016/j.ahj.2007.04.065

12. Kee F, McDonald P, Gaffney B. Risks and benefits of coronary angioplasty: the patients perspective: a preliminary study. Qual Health Care QHC. 1997;6(3):131-139. doi:10.1136/qshc.6.3.131

13. Kureshi F, Jones PG, Buchanan DM, Abdallah MS, Spertus JA. Variation in patients' perceptions of elective percutaneous coronary intervention in stable coronary artery disease: cross sectional study. BMJ. 2014;349(sep08 8):g5309. doi:10.1136/bmj.g5309

14. Rothberg MB, Sivalingam SK, Kleppel R, Schweiger M, Hu B, Sepucha KR. Informed decision making for percutaneous coronary intervention for stable coronary disease. JAMA Intern Med. 2015;175 (7):1199-1206. doi:10.1001/jamainternmed.2015.1657

15. Chan PS, Patel MR, Klein LW, et al. Appropriateness of percutaneous coronary intervention. JAMA. 2011;306(1):53-61. doi:10.1001/ jama.2011.916

16. Hannan EL, Cozzens K, Samadashvili Z, et al. Appropriateness of coronary revascularization for patients without acute coronary syndromes. $J$ Am Coll Cardiol. 2012;59(21):1870-1876. doi:10.1016/j.jacc.2012.01.050

17. Coylewright M, Dick S, Zmolek B, et al. PCI choice decision aid for stable coronary artery disease: a randomized trial. Circ Cardiovasc Qual Outcomes. 2016;9(6):767-776. doi:10.1161/ CIRCOUTCOMES.116.002641

18. Coylewright M, Shepel K, Leblanc A, et al. Shared decision making in patients with stable coronary artery disease: PCI choice. PLoS One. 2012;7(11):e49827. doi:10.1371/journal.pone.0049827

19. Kelly-Blake K, Clark S, Dontje K, et al. Refining a brief decision aid in stable CAD: cognitive interviews. BMC Med Inform Decis Mak. 2014;14(1):10. doi:10.1186/1472-6947-14-10

20. Holmes-Rovner M, Kelly-Blake K, Dwamena F, et al. Shared decision making guidance reminders in practice (SDM-GRIP). Patient Educ Couns. 2011;85(2):219-224. doi:10.1016/j.pec.2010.12.028

21. Morgan MW, Deber RB, Llewellyn-Thomas HA, et al. Randomized, controlled trial of an interactive videodisc decision aid for patients with ischemic heart disease. $J$ Gen Intern Med. 2000;15 (10):685-693. doi:10.1046/j.1525-1497.2000.91139.x

22. Spertus JA, Bach R, Bethea C, et al. Improving the process of informed consent for percutaneous coronary intervention: patient outcomes from the patient risk information services manager (ePRISM) study. Am Heart J. 2015;169(2):234-241.e1. doi:10.1016/j.ahj.2014.11.008
23. Fowler FJ, Gallagher PM, Bynum JPW, Barry MJ, Lucas FL, Skinner JS. Decision-making process reported by medicare patients who had coronary artery stenting or surgery for prostate cancer. $J$ Gen Intern Med. 2012;27(8):911-916. doi:10.1007/s11606-0122009-5

24. Spertus JA, Winder JA, Dewhurst TA, et al. Development and evaluation of the Seattle Angina questionnaire: a new functional status measure for coronary artery disease. J Am Coll Cardiol. 1995;25 (2):333-341. doi:10.1016/0735-1097(94)00397-9

25. Gordon HS, Paterniti DA, Wray NP. Race and patient refusal of invasive cardiac procedures. J Gen Intern Med. 2004;19 (9):962-966. doi:10.1111/j.1525-1497.2004.30131.x

26. Kressin NR, Chang B-H, Whittle J, et al. Racial differences in cardiac catheterization as a function of patients' beliefs. Am J Public Health. 2004;94(12):2091-2097. doi:10.2105/AJPH.94.12.2091

27. Farrell MH, Murphy MA, Schneider CE. How underlying patient beliefs can affect physician-patient communication about prostate-specific antigen testing. Eff Clin Pract. 2002;5(3):120-129.

28. LaVeist TA, Nickerson KJ, Bowie JV. Attitudes about racism, medical mistrust, and satisfaction with care among African American and white cardiac patients. Med Care Res Rev. 2000;57(Suppl 1):146-161. doi:10.1177/1077558700057001S07

29. Schecter AD, Goldschmidt-Clermont PJ, McKee G, et al. Influence of gender, race, and education on patient preferences and receipt of cardiac catheterizations among coronary care unit patients. $\mathrm{Am}$ $J$ Cardiol. 1996;78(9):996-1001. doi:10.1016/S0002-9149(96) 00523-1

30. Oddone EZ, Horner RD, Diers T, et al. Understanding racial variation in the use of carotid endarterectomy: the role of aversion to surgery. J Natl Med Assoc. 1998;90(1):25-33.

31. van Ryn M, Burke J. The effect of patient race and socio-economic status on physicians' perceptions of patients. Soc Sci Med. 2000;50 (6):813-828. doi:10.1016/s0277-9536(99)00338-x

32. Mitchell SE, Paasche-Orlow MK, Orner MB. Patient decision control and the use of cardiac catheterization. Glob Adv Health Med. 2015;4 (4):24-31. doi:10.7453/gahmj.2015.036

33. Lin GA, Dudley RA, Redberg RF. Why physicians favor use of percutaneous coronary intervention to medical therapy: a focus group study. $J$ Gen Intern Med. 2008;23(9):1458-1463. doi:10.1007/s11606-008-0706-x

34. Lin GA, Dudley RA, Redberg RF. Cardiologists' use of percutaneous coronary interventions for stable coronary artery disease. Arch Intern Med. 2007;167(15):1604-1609. doi:10.1001/archinte.167.15.1604
Patient Preference and Adherence

\section{Publish your work in this journal}

Patient Preference and Adherence is an international, peer-reviewed, open access journal that focusing on the growing importance of patient preference and adherence throughout the therapeutic continuum. Patient satisfaction, acceptability, quality of life, compliance, persistence and their role in developing new therapeutic modalities and compounds to optimize clinical outcomes for existing disease states are major areas of interest for the journal. This journal has been accepted for indexing on PubMed Central. The manuscript management system is completely online and includes a very quick and fair peer-review system, which is all easy to use. Visit http:// www.dovepress.com/testimonials.php to read real quotes from published authors. 